\title{
Insecure Attachment and the Correlation with Joining Insurgent Groups in Colombia
}

\section{Vínculo inseguro y su correlación con el ingreso a grupos insurgentes en Colombia}

\author{
Gladys Pérez Di Vito \\ The New School for Social Research, New York, USA
}

\begin{abstract}
This study examined early childhood experiences in ex-insurgents from a Colombian paramilitary group (AUC) in order to determine whether their shared profile of difficult attachment is related with their joining the insurgency. One hundred fifty seven young adults were assessed using the Parental Bonding Instrument (PBI) (Parker, 1986). Results indicate that $99.4 \%$ of the sample $(n=156)$ received insecure attachment classification and $(n=1)$ received optimal parenting. The study highlights the importance of responsive and supportive care given during childhood.
\end{abstract}

Key words: Attachment, bond, parenting, aggression, insurgency.

\section{RESUMEN}

Este estudio examina experiencias infantiles en ex-insurgentes del grupo colombiano paramilitar Autodefensas Unidas de Colombia (AUC) para determinar si existe relación entre vínculos afectivos inseguros/difíciles en la infancia y el ingreso a grupos insurgentes. Ciento cincuenta y siete jóvenes adultos respondieron el cuestionario de vínculo parental (PBI) (Parker, 1986). Los resultados indicaron que el 99.4\% de la muestra (156) fue clasificado con un vínculo afectivo inseguro y $6 \%(\mathrm{n}=1)$ recibió un vínculo afectivo óptimo. El estudio resalta la importancia del apoyo responsable de los padres en la infancia.

Palabras clave: Vínculo, afecto, apego, agresión, insurgencia.

Artículo recibido/Article received: Febrero 16, 2009/February 16, 2009, Artículo aceptado/Article accepted: Mayo 7, 2009/May 7/2009 Dirección correspondencia/Mail Address: Gladys Pérez Di Vito, The New School for Social Research, 155 Saxon Drive, Mamaroneck NY. 10543, USA, e-mail: Gladysbell1@aol.com

International Journal of Psychological Research esta incluida en PSERINFO, Centro de Informacion Psicologica de Colombia, GOOGLE SCHOLARS y DIALNET. Algunos de sus articulos estan incluidos en Social Science Research Network y está en proceso de inclusion en diversas fuentes y bases de datos internacionales.

International Journal of Psychological Research is included in PSERINFO, Centro de Información Psicológica de Colombia, GOOGLE SCHOLARS and DIALNET. Some of its articles are included in Social Science Research Network, and it is in the process of inclusion in a variety of sources and international databases. 
According to the Attachment theory, the type of attachment pattern the infant forms is largely determined by the quality of caregivers' responsiveness. Drawing on his clinical observations of orphaned and delinquent children and ideas from etiology, systems theory, and cognitive science, Bowlby $(1969,1982)$ proposed that important qualities of the infant-caregiver relationship were related to significant aspects of child behavior and emotional experience, as well as to the formation of healthy and unhealthy developmental trajectories (see Lopez, 2003).

Furthermore, Bowlby (1979) argued that early separation from attachment figures, or absence of an attachment figure, would predispose a person to the development of emotional coldness, affectionless character and lack of empathy in adulthood. Empathy has been described as a moral emotion that leads individuals to understand and share another's emotional state or situation, signs of empathy emerge very early in development (Cohen \& Strayer, 1996).

One of the common characteristics of the insurgent group is the level of aggression. According to Weinshenker \& Siegel (2002), two primary types of aggression have been distinguished: reactive (hostile or affective) and instrumental (predatory or premeditated). Reactive aggression is defined as being impulsive, unplanned, and driven by heightened emotional arousal, and as occurring as a reaction to some perceived imminent provocation. Instrumental aggression is proactive rather than reactive and is a planned, calculated behavior that is goal directed and characterized by an absence of emotion. This study took into account instrumental aggression since the activities the insurgents carry out are well planned and goal oriented. In this connection the high proportion of instrumental violence is marked by lack of empathy. The presence of empathy is associated with pro-social behavior, whereas its absence appears to act as a risk factor for aggressive behavior in children and adults.

Similarly, Van IJzendoorn, et al. (1997), examined the relationship between attachment representations and personality disorders, and found that secure attachment representations were virtually absent in the sample of 40 dutch men held in a forensic psychiatric hospital for the commission of serious crimes. The authors found that separation from attachment figures in childhood was related to current insecure attachment as well as to personality disorders. Bowlby theorized that early attachment-related experiences with primary caregivers are represented in the form of cognitive schema, referred to as an Internal Working Model (IWM) of self and others (Lopez, 2003). Infants who received warm, responsive, and non-intrusive care from their attachment figures were assumed to form a secure attachment model. By contrast, infants who experienced their caregivers as intrusive, inconsistently responsive, or as consistently rejecting were likely to form either an anxious or avoidant orientation.

While attachment literature offers strong evidence for the continuity of attachment patterns over time (e.g., Collins \& Read 1990; Elicker, Englund, \& Sroufe, 1992; Hazan \& Shaver, 1994; Kirkpatrick \& Hazan, 1994; Overbeek, et al., 2007), research has indicated that the attachment patterns are generally stable over the first several years of life but can change if the child's social circumstances change. Nevertheless, the notion of likelihood of modification of internal schema in an individual's future does not de-emphasize the danger of inconsistent caregiving in one's past. As with any cognitive construction, IWM are resistant to change in part because they tend to be over-learned and operate out of awareness, and in part because the default strategy for processing incoming information is to assimilate it to existing schemas rather than modify the schemas to accommodate the information (Piaget, 1952, cited by Hazan \& Shaver, 1994). IWM, with age, may become less consciously accessible and more resistant to change (Howes, Hamilton, \& Philipsen, 1998). As Shorey and Snyder (2006) explain, attachment styles become the roadmaps (i.e., working models) for negotiating social environments and they act as self-fulfilling prophecies where individuals behave in ways that elicit schema-congruent behaviors from others.

According to Bowlby, the attachment behavioral system was gradually "designed" by natural selection to regulate proximity to an attachment figure (see Fraley \& Brumbaugh, 2004). Therefore, individuals strive to reestablish a desirable level of proximity to the attachment figure. Previous research suggests that insecure attachment is associated with lower self-evaluations (Srivastava \& Beer, 2005). Thus, perhaps the proximity seeking in socially undesirable groups (rather than socially acceptable groups, as are religious groups, for instance) may be direct consequence of poor self-evaluations that result from insecure attachment. Drawing these parallels may help understand one of the factors that play part in the participants' decision in this study to join the insurgency. It may be suggested that the group served a function of "surrogate attachment figure" to these members. In fact, the hypothesis assumes that individuals who have experienced insecure, as opposed to secure, attachment relationships are in greater need to establish compensatory attachment relationships to obtain felt security (Kirkpatrick, 1992).

Bowlby states the attachment activation occurs in the context of stress. The situation of war in Colombia, the economical and social difficulty and confusion may trigger internal insecurity; and at the moment, the possibility of being an insurgent in Colombia perhaps legitimates and might even compensate the internal insecurity through the affiliation to the insurgency, this option becoming a tempting solution to assuage distress, which seems to be a valid consequence of an insecure attachment history.

Not all individuals under similar circumstances surrender to the vicissitudes of life. On the contrary, they acquire remarkable capacity to develop adaptive cognitive appraisals, extensive social skills, and constructive methods 
of coping with emotional distress. While discrepancy exists among scholars in regards to labeling such exceptional individual (e.g., Foreman, 1966; Kobasa, 1982; Maslow, 1970) the notion of the critical role of early attachment relationships in adjustment to life is shared by many (e.g., Garmezy, 1991; Luthar 2003; Masten, 1991). The internalized dispositions that result from one's early experiences with attachment figures promote feelings of security or threat and largely determine a person's resilience or vulnerability to stressful life events. In line with this view, Florian \& Mikulincer (1998) argued that secure adult attachment functions as an "inner resource' that may help the individual cope successfully with life's adversities", whereas "insecure attachment can be viewed as a risk factor that may detract from the individuals' resilience in times of stress (Lopez, Mitchell, \& Gormley, 2002).

Bowlby's (1973) attachment theory claims that proximity maintenance to significant others is a psychoevolutionary device that helps people cope with distress-eliciting events. While Bowlby's proximity seeking notion may be an impetus behind the participant's decision to bond with the insurgency group, a group that may provide and satisfy some physical security, the fundamental assumption of the attachment theory is the importance of provision of psychological security as well, but part of the inner insecure does not allow it to see the risk (Baumeister \& Leary, 1995). In understanding the attachment process in adolescence the importance has been given to the concept of "felt security" rather than solely physical proximity. Furthermore, attachment theory postulates that emotional well-being in childhood, will depend in part on having an accessible attachment figure who can serve as a reliable safe haven in times of need (Collins \& Feeney, 2000). This explains in part the risk of the insurgent faces in order to kill others, for example, "to belong to a group, to feel someone's proximity".

\section{HYPOTHESIS}

The current study tested a hypothesis, that individuals who had joined the insurgent group had experienced inadequate (neglectful, constraining and affectionless control) caregiving in childhood, consequently are expected to exhibit an insecure attachment history on the attachment measure of early childhood. Therefore, I expect to find high frequency of individuals in the group with insecure childhood attachment styles.

\section{METHOD}

\section{Participants}

The data were obtained from a representative sample of former ex-insurgent adults of AUC from Colombia. The initial 162 people that participated in the studies are currently members of the "Peace
\& Reintegration Program" in Colombia, which is aiding these individuals in their reintegration process into society. Participants received a baseball hat with the New School $\log 0$ as a souvenir for their participation. Three of the participants refused to sign a consent form and their responses to the questionnaires were dismissed from the study. Responses of two participants who failed to answer most of the questions on PBI were not included. Data for the analyses in this study were collected from $\mathrm{N}=157$ individuals (142 male and 15 female). The mean age of the participants was 26.0 years, with a range from $20-35$. The median education level was less than eighth grade, with a range from less than a $5^{\text {th }}$ grade to completion of post-high school training. The participants' SES was noted at or below poverty level, for a majority of the subjects, according to the Colombian standards.

\section{Procedure}

An informed consent form was obtained from the subjects. Confidentiality for their questionnaire responses was assured to all participants. Each subject was identified with a code number. Participants were given a questionnaire packet containing the measures to be described below. In addition to verbal and written instructions, participants were advised to ask questions in case of need of further clarification. Furthermore, the experimenter stressed the importance of answering questions honestly.

\section{Instruments}

Early attachment-related experiences with attachment figures are postulated to form a secure, anxious or avoidant orientation (see Lopez, 2003). Early attachment style was assessed based on early parental care using the Parental Bonding Instrument (PBI) (Parker, 1986). The instrument was translated into Spanish and proofread by an independent bilingual colleague and finally corrected by Spanish-speaking psychologists. Few modifications were applied when the translation was compared to the 25 items, Likert-type scale (ranging from 3-very likely, 2- moderately likely, 1-moderately unlikely, to 0-very unlikely). PBI consists of two scales, care (12 items) and overprotection (13 items); these items measure parental styles towards the child. The instrument assesses care for both mother and father separately. The combination of the two scales offers four types of parenting: Optimal parenting (high care and low overprotection), Affectionless Control (high overprotection and low care), Affectionate Constraint (high care and high overprotection) and Neglectful Parenting (low care and low overprotection).

Parker, Tupling, \& Brown (1979), reported testretest reliability scores of .76 for the care scale and .63 for the overprotection scale; inter-rate reliability of .85 on the care dimension and .69 on the overprotection dimension, and current validity scores of .77 and .78 for the care dimension and .48 and .50 for the overprotection 
dimension. Responses on the measure provide continuous scores on the two dimensions of attachment-related anxiety and avoidance in childhood.

To come up with the PBI_Care and PBI_OverProtection scales, I took the following steps: First I added all the respective Care and Over-Protection items to come up with a gross-index. Second, I used the cut off points suggested by Parker, Tupling, and Brown (s.f.) to determine whether the gross Care and Over-Protection indexes indicated subjects' early experiences regarding parental care (caring or over- protective). For mothers, a care score above 27.0 indicates that the mother was caring; and an over-protection score above 13.5 points indicates that the mother was over-protective. For fathers, the corresponding cut-off scores are 24.0 for care and 12.5 for overprotection.

After categorizing mothers and fathers parenting style as either "high caring" or " low caring" and as either being "low-overprotective" or "high-overprotective", I was able to determine the type of parental bonding experienced by respondents during childhood. The four possible types of Parental Bonding experience that emerge during childhood are: Optimal Parenting; Affectionate Constraint; Affectionless Control; Neglectful Parenting.

Finally, to facilitate analysis, I converted the Parental Bonding variable into a binomial that identifies individuals who experienced "Optimal Parenting" from all others. As noted above, I expected that respondents who had not experienced "Optimal Parenting" during their childhood were more likely to join the insurgency.

\section{RESULTS}

The first purpose was to determine whether the majority of the number of individuals in the sample who had previously joined the insurgency group had experienced insecure attachment style in childhood or not.

Table 1 indicates that $99.4 \%$ (156) of individuals received inadequate parenting, conversely only one person in the study classified as secure on the self-report measure, which corresponds to optimal parenting (high care and low overprotection) in this individual's childhood. Furthermore, $53.5 \%$ (84) of participants reported to experience affectionless control (low care and high overprotection from parent(s)) which corresponds to fearful-avoidant (disorganized) attachment style; $44.6 \%$ (70) experienced affectionate constraint (high care, and high overprotection) in their childhood which corresponds to preoccupied (anxious) attachment style. Finally, 1.3\% (2) participants received dismissive (avoidant) childhood attachment classification which corresponds to neglectful (low care and low overprotection) parenting style on PBI.

International Journal of Psychological Research
Table 1. Parenting Bonding \& Attachment Classification

\begin{tabular}{ll}
\hline \multicolumn{1}{c}{ EXPERIENCE } & \multicolumn{1}{c}{ CLASSIFICATION } \\
\hline $\begin{array}{l}\text { High Care /Low Overprotection } \\
\text { (Optimal Parenting) }\end{array}$ & Secure (Secure) \\
$1(.6 \%)$ & \\
High Care/ High Overprotection & Anxious (Preoccupied) \\
(Affectionate Constraint) & \\
$70(44.6 \%)$ & \\
Low Care/Low Overprotection & Avoidant (Dismissive ) \\
(Neglectful Parenting) & \\
$2(1.3 \%)$ & \\
Low Care/High Overprotection & Disorganized (Fearful- \\
(Affectionless Control) & Avoidant ) \\
$84(53.5 \%)$ & \\
\hline
\end{tabular}

Note. $99.4 \%$ of the sample received insecure childhood attachment

Table 2. Attachment style in childhood on PBI

\begin{tabular}{cccc}
\hline $\begin{array}{c}\text { Secure } \\
F(\%)\end{array}$ & $\begin{array}{c}\text { Preoccupied } \\
F(\%)\end{array}$ & $\begin{array}{c}\text { Dismissive } \\
F(\%)\end{array}$ & $\begin{array}{c}\text { Fearful/ } \\
\text { Avoidant } \\
F(\%)\end{array}$ \\
\hline $1(.6 \%)$ & $70(44.6 \%)$ & $2(1.3 \%)$ & $84(53.5 \%)$ \\
\hline
\end{tabular}

In Table 2 only one person $(.6 \%)$ received a secure attachment classification in childhood, 84 (53.0\%) participants were classified as fearful-avoidant in childhood, 70 (44.6\%) as anxious during childhood; Attachment literature suggests that individuals with dismissive attachment style have a positive view of self and negative view of others which may explain lack of empathy with that childhood attachment style in the sample, based on attachment literature regarding support seeking behavior of individuals with dismissive attachment classification, one may predict their likelihood of dropping out from the program.

\section{DISCUSSION}

The main objective of the study was to examine the extent to which individuals' early mental representations influence their social adjustment. The study illustrates a strong association between poor attachment history and poor social adjustment therefore leading to joining the insurgency.

The results highlight the importance of supportive relationships throughout one's life. Individual's attachment organization has been implicated to be integrally related to numerous aspects of functioning and social adjustment (Allen, Moore, Kuperminc, \& Bell, 1998). In the study I 
utilized attachment theory to aid our understanding of violence in early adulthood. Guided by attachment theory the study examined early childhood experiences in exinsurgents to determine whether (as predicted) they share a profile of difficult childhood experiences. Although the study was largely exploratory, the following general hypothesis was advanced: High frequency of insecure childhood profiles among insurgent.

Bowlby (1988) suggested that attachment refers to the emotional bond experienced with another who is sensed as a source of security and who provides a secure base anchoring exploration (Fouladi, McCarthy, \& Moller, 2002). Based on this notion, I claim that the insurgent group used to play an important role as an attachment figure for the former insurgents. Even though there are fundamental differences between interpersonal and group relationships (see Smith, Murphy, \& Coats, 1999 for review), managing and regulating closeness and dependence with both individual relationship partners (particularly caregivers, partners) and groups are equally essential to survival in human evolutionary history (Smith, et al, 1999). In addition, it is no surprise that the same two dimensions (attachment anxiety and avoidance) emerge in both of these domains (Smith, et al., 1999). Insecure attachment has been shown to lead to less support seeking behavior (see Vogel \& Wei, 2005). Thus, participants in the sample were prone to join a group that offered "less support, higher risk". The insurgents know that they can be killed during any activity or be killed by one of the members of the group if they disobey the rules. However, attachment theory postulates that the experience of distress provokes an individual to seek another because of an "inborn need to seek safety" (see Crowell \& Waters, 2005).

The idea that empathy and concern for others acts as a deterrent to engaging in instrumental violence (like what insurgency performs) is supported by Hirschi (1969) and Bowlby (1979). Hirschi stated that many people refrain from engaging in violent behavior (delinquency) because they fear losing their relationships with others. Bowlby argued that attachment is related to violence, by suggesting that early separation from attachment figures, or absence of attachment figures, would predispose a person to the development of emotional coldness, or affectionless character. In fact, 70 participants of the sample were exposed to affection constrain parenting and 84 participants were exposed to affectionless control parenting. The sum of those parenting styles represented $98.1 \%$ of the sample in this study.

The first analyses examined individuals' attachment profile in childhood assessing the quality of their relationship with early attachment figures. Results revealed that only one individual $(.6 \%)$ in the sample who had optimal parenting (measured by PBI) exhibited secure attachment classification in childhood while 70 people (44.6\%) reported Preoccupied (anxious), 2 people (1.3\%) dismissive (avoidant) and 84 people (53.5\%) Fearful-
Avoidant (disorganized); being the last three classifications characteristics of insecure attachment. Attachment theory claims that individuals, depending on the type of relationship experienced with their attachment figures, will form IWM which are defined as the individuals' representations of the world, of their attachment figures, and of themselves and are used specifically to organize information. Yet, these are not rigid representational systems but can be triggered and modulated according to the actual environmental and interpersonal circumstances (Vermigli \& Toni, 2004). The current war in Colombia is a permanent trigger to activate the attachment system. Attachment theory posits that IWM influence how we respond to and interpret others' actions which resulted from early parent-child interactions and are carried forward into future relationships (see Collins \& Read, 1990). Bringing into the account that only one of the examples of this study experienced optimal parenting, it can be claimed that a high frequency $(99.4 \%)$ of the insurgents experienced insecure attachment, thus, joining the insurgency, is coherent with their IWM. In this respect, they are violent towards others, they lack empathy and they interpret delinquency as something common to do according with their IWM.

The second set of analyses led to an unexpected result, only two people $(1.3 \%)$ in the sample were exposed to neglectful parenting, this result may suggest that neglectful parenting isn't a prevalent characteristic in regards to joining the insurgency. From a dynamic and attachment perspective this sounds quiet revealing. It is logical to think that to join an insurgent group people need a little bit of energy and determination to make that move; it isn't a secure move, but a move to continue looking for secure attachment for proximity to attachment figure. Many researchers have observed that the effects of neglect on young children were even more deleterious than those of abuse. Indeed, compared to abused children, neglected children are more passive, feel more helpless (freeze character) (Crittenden, 2000), are less happy, less creative, more rigid and more withdrawn (Erickson \& Egeland, 2002). Consequently, the ex-insurgent would not likely be passive or hopeless in order to join the insurgency.

Research has supported that children who in the past experienced an insecure attachment representation with their caretaker can develop secure relationships with other adults in the future (Venet, Bureau, Gosselin, \& Capuao, 2007). Furthermore, Kirkpatrick and Hazan (1994) demonstrated that insecure individuals can become more secure when matched with a secure partner. Representations are updated and revised in light of new experiences in such a way that older representations are eventually "overwritten" (Fraley \& Brumbaugh, 2004). In light of this notion, I can state that the Colombian current Reintegration program can match a new secure representation, a new figure to the ex-insurgents who are still seeking for a secure attachment that they didn't receive in the childhood from parents of caregivers. 
I do not suggest, however, that early attachment history could be wiped out clean, "given that poor adaptation and history are not "erased' by change" (Shaver and Clark, 1994; Sroufe, Egeland, \& Kreutzer,1990); earlier patterns may be reactivated, and early history adds to current circumstances in predicting current adaptation" (Sroufe, Carlson, \& Shulman, 1993), rather, I emphasize the critical role of the Reintegration program in the process of change in one's attachment system. The implication is that attachment history needs not be "overly deterministic" of one's future; changes will come for better or worse. Powerful environmental events, especially those that disconfirm, overwhelm, or otherwise erode the integrity of the working model may precipitate significant revisions of the model toward either greater or lesser security and thus result in discontinuities in the impact of the earlier models on current and future development (Lopez \& Brennan, 2000)

Bowlby (1988) believed insecure IWM's can be revised in the context of a positive therapeutic encounter. From a clinical perspective, the study offers hope that with corrective, confirming experiences with sensitive attachment-like figures, such as partner or clinician (The Reintegration Program per se), modification of psychological functioning is possible and is related to secure-base experiences offered by a new care giving environment.

In closing, attachment theory accentuates the importance of supportive relationships for affective cognitive development of the child and the socio-emotional development of the adult.

Several limitations of the present study constrain from drawing firmer conclusions. For instance, the study relied exclusively on self-report measures of the significant variables which are open to different biases. For example, the accuracy of participants' memory for remote events may be challenged, however, it should be also noted that the attachment measures were not designed to assess the accuracy of memory for childhood events but rather the manner in which such events are recalled (see Lopez \& Brennan, 2000).

This study was conducted in a unique cultural context and examined individuals from low SE's. Therefore, caution is advised when trying to generalize its findings to other contexts and social groups. Furthermore, according to Mallinckrodt and Wang (2004), until the concept of adult attachment security is extensively studied in other cultures, we cannot confidently conclude that a Western model of secure attachment is equally applicable across different cultures. On the other hand, however, similar patterns of infant-caregiver attachment that emerged from Ainsworth groundbreaking study in both settings, Baltimore and Uganda, became the basis for claiming that attachment theory constructs are culturally universal (see Wei, Russell, Mallinckrodt, \& Zakalik, 2004).

Small sample size and design prevent to draw causal inferences. No quantitative methods for verification of the semantic equivalence of the translated instrument were conducted. Some important issues need to be addressed in future research. For instance, it would be interesting to fully investigate a wider range of dependent variables; influence of social support on attachment, using additional measures and control group. Despite the limitations, the results of the current study stress the importance of the responsive caregiving during childhood, and later life as well.

\section{REFERENCES}

Allen, J.P., Moore, C., Kuperminc, G., \& Bell K. (1998). Attachment and Adolescent Psychological Functioning, Child Development, 69(5), 1406-1419.

Baumeister, R.F., \& Leary, M.R. (1995). The Need to Belong: Desire for Interpersonal attachments as a Fundamental Human Motivation. Psychological Bulletin, 117(3), 497-529.

Bowlby, J. (1969). Attachment and loss: Vol. 1. Attachment. NY, USA: Basic Books.

Bowlby, J. (1973). Attachment and loss: Vol. 2. Separation: Anxiety and anger. NY, USA: Basic Books.

Bowlby, J. (1979). On knowing what you are not supposed to know and feeling what you are not supposed to feel. The Canadian Journal of Psychiatry, 24(5), 403-408.

Bowlby, J. (1982). Attachment and loss: Retrospect and prospect. American Journal of Orthopsychiatry, 52(4), 664-678.

Bowlby, J. (1988). A secure Base: Parent-child attachments and Healthy Human Development. New York, USA: Basic Books.

Cohen, D., \& Stayer, J. (1996). Empathy in conductdisordered and comparison youth. Developmental Psychology, 32(6), 988-998.

Collins, N.L., \& Feeney, B.C. (2000). A Safe Haven: An Attachment Theory Perspective on Support Seeking and Caregiving in Intimate Relationships. Journal of Personality and Social Psychology, 78(6), 1053-1073.

Collins, N.L., \& Read, S.J. (1990). Adult attachment, working models, and relationship quality dating couples. Journal of Personality and Social Psychology, 54(4), 644-663.

Crittenden, P. M. (2000). A dynamic-maturational approach to continuity and change in pattern of attachment. The organization of attachment relationships: Maturation, culture, and context. New York, NY: Cambridge University Press.

Crowell, J., \& Waters, E. (2005). Attachment representations, secure-base behavior, and the evolution of adult relationships: The Stony Brook Adult Relationship Project. In K. E. Grossmann, K. Grossmann, \& E. Waters, Attachment from infancy to adulthood: The major longitudinal studies. New York, NY: Guilford Publications 
Elicker, J., Englund, M., \& Sroufe, L.A. (1992). Predicting peer competence and peer relationships in childhood from early parent-child relationships. In R. D. Park, \& G.W. Ladd, Family-peer relationships: Models of linkage. New Jersey, USA: Lawrence Erblaum Associates, Inc.

Erickson, M.F., \& Egeland, B. (2002). Child neglect. In J.E.B. Myers, L. Berliner, J. Briere, C.T. Hendrix, C. Jenny, \& T.A. Reid (Eds.), The APSAC handbook on child maltreatment ( $2^{\text {nd }}$ ed., pp. 3-20). Thousand Oaks, CA, USA: Sage.

Florian, V., \& Mikulincer, M. (1998). Terror management in childhood: Does death conceptualization moderate the effects of mortality salience on acceptance of similar and different others? Personality and Social Psychology Bulletin, 24(10), 1104-1112.

Foreman, M.E. (1966). Some empirical correlates of psychological health. Journal of Counseling Psychology, 13(1), 3-11.

Fouladi, R. T., McCarthy, C. J., \& Moller, N.P. (2002). Paper-and-pence or online? Evaluating mode effects on measures of emotional functioning and attachment. Assessment, 9(2), 204-215.

Fraley, R. C., \& Brumbaugh, C.C. (2004). A dynamical systems approach to conceptualizing and studying stability and change in attachment theory. Adult attachment: Theory, research, and clinical implications. New York, NY, USA: Guilford Publications.

Garmezy, N. (1991). Resilience and vulnarbility to adverse developmental outcomes associated with poverty. American Behavioral Scientist, 34(4), 416-430.

Hazan, C., \& Shaver, P.R. (1994). Deeper into attachment behavior. Psychological Inquiry, 5(1), 68-79.

Hirschi, T.W. (1969). Infraction as action: A study of the antecedents of illegal acts. Dissertation Abstracts International, 29(9-A), 32-33.

Howes, C., Hamilton, C.E., \& Philipsen, L.C. (1998). Stability and Continuity of Child-Caregiver and ChildPeer Relationships. Child Development, 69(2), 418-426.

Kirkpatrick, L.A. (1992). An Attachment Theory Approach to the Psychology of Religion. The International Journal for the Psychology of Religion, 2, 3-28.

Kirkpatrick, L.A., \& Hazan, C. (1994). Attachment styles and close relationships: A four-year prospective study. Personal Relationships, 1(2), 123-142.

Kobasa, S. (1982). Commitment and coping in stress resistance among lawyers. Journal of Personality and Social Psychology, 42(4), 707-717.

Lopez, F.G. (2003). The assessment of adult attachment security. In S.J. Lopez, \& C.R. Snyder (Eds.), Positive psychological assessment: A handbook of models and measures (pp. 285-299). Washington, DC, USA: APA Press.

Lopez, F.G., \& Brennan, K.A. (2000). Dynamic processes underlying adult attachment organization: Toward an attachment theoretical perspective on the healthy effective self. Journal of Counseling Psychology, 47(3), 283-300.

Lopez, F., \& Mitchell, P., \& Gormley, B. (2002). Adult attachment orientations and college student distress: Test of a meditational model. Journal of Counseling Psychology, 49(4), 460-467.

Luthar, S. (Ed.) (2003). Resilience and vulnerability: Adaptation in the context of childhood adversities. New York, NY, USA: Cambridge University Press.

Mallinckrodt, B., \& Wang, C-C. (2004). Quantitative methods for verifying semantic equivalence of translated research instruments: A Chinese version of the experiences in close relationship scale. Journal of Counseling Psychology, 51(3), 368-379.

Maslow, A. H. (1970). New introduction: Religions, values, and peak experiences. Journal of Transpersonal Psychology, 2(2), 83-90.

Masten, A.S. (1991). Learning from children who overcome adversity. PsychCRITIQUES. 6(2), 101-102.

Overbeek, G. Håkan, S. Vermulst, A., Ha, T., Rutger C.M., \& Engels, E. (2007). Parent-Child Relationships, Partner Relationships, and Emotional Adjustment: A Birth-to-Maturity Prospective Study. Developmental Psychology, 43(2), 429-437.

Parker, G. (1986). Validating an experiential measure of parental style: The use of a twin sample. Acta Psychiatrica Scandinavica, 73(1), 22-27.

Parker, G, Tupling, H., \& Brown,L.B (1979) A parental bonding instrument. British Journal of Medical Psychology, 52, 1-10.

Parker, G., Tupling, H., \& Brown, L.B. (s.f.). Parental Bonding Instrument (PBI). Retrieved on 11/06/07 from www.blackdoginstitute.org.au/docs/ParentalBondingIns trument.ooo.pdf

Shaver, P.R., \& Clark, C.L. (1994). The psychodynamics of adult romantic attachment. Empirical perspectives on object relations theory. Washington, DC, USA: American Psychological Association.

Shorey, H.S., \& Snyder, C.R. (2006). The Role of Adult Attachment Styles in Psychopathology and Psychotherapy outcomes. Review of General Psychology, 10(1), 1-20.

Smith, E.R., Murphy, J., \& Coats, S. (1999). Attachment to Groups: Theory and Measurement. Journal of Personality and Social Psychology, 77(1), 94-110.

Sroufe, L.A., Carlson, E., \& Shulman, S. (1993). Individuals in relationships: Development from infancy through adolescence. Studying lives through time: Personality and development. Washington, DC, USA: American Psychological Association.

Sroufe, L.A., Egeland, B., \& Kreutzer, T. (1990). The fate of early experience following developmental change: Longitudinal approaches to individual adaptation in childhood. Child Development, 61(5), 1363-1373.

Srivastava, S., \& Beer, J.S. (2005). How Self-Evaluations Relate to Being Liked by Others: Integrating 
Sociometer and Attachment Perspectives. Journal of Personality and Social Psychology, 89(6), 966- 977.

Van IJzendoorn, M.H., Feldbrugge, J.T.T.M., Derks F.C.H,. de Ruiter, C., Verhagen, M.F.M, Philipse, M.W.G. van der Staak, C.P.F., \& Riksen-Walraven, J.M.A. (1997). Attachment Representations of Personality-Disordered Criminal Offenders American Journal of Orthopsychiatry, 6(3), 449-459.

Venet, M., Bureau, J.F., Gosselin, C., \& Capuano, F. (2007). Attachment Representations in a Sample of Neglected Preschool-Age Children. School Psychology International, 28(3), 264-293.

Vermigli, P., \& Toni, A. (2004). Attachment and Field Dependence: Individual Differences in Information Processing. European Psychologist, 9(1), 43-55.

Vogel, D. L., \& Wei, M. (2005). Adult attachment and help-seeking intent: The mediating roles of psychological distress and perceived social support. Journal of Counseling Psychology, 52(3), 347-357.

Wei, M., Russell, D.W., Mallinckrodt, B., \& Zakalik, R.A. (2004). Ethnic groups: Factor structure, structured means and associations with negative mood. Journal of Counseling Psychology, 51(4), 408-417.

Weinshenker, N., \& Siegel, A. (2002). Bimodal classification of aggression: Affective defense and predatory attach. Aggression and Violent Behavior, 7(3), 237-250. 